\title{
Expression of hydrogen sulfide, hydrogen-sulfide synthase and cyclooxygenase-2, and their mechanisms of action in amniotic tissues
}

\author{
Ming Liu', Dan Liu', Tao Duan', Xing-ji You ${ }^{3}$, Lu Gao ${ }^{3}$, Xin Ni ${ }^{3}$ \\ ${ }^{1}$ Department of Obstetrics and Gynecology, Shanghai First Maternity and Infant Hospital, Tongji University School of Medicine, \\ Shanghai 201204, ${ }^{2}$ Department of Obstetrics and Gynecology, The Second Hospital of Shandong University, Jinan, Shandong \\ 250000, ${ }^{3}$ Department of Physiology, The Second Military Medical University, Shanghai 200433, China
}

*For correspondence: Email: es0749@163.com

Sent for review: 2 February 2018

Revised accepted: 27 April 2018

\begin{abstract}
Purpose: To investigate the expressions of cystathionine $\beta$-synthase (CBS), cystathionine $\gamma$ - lyase (CSE) and cyclooxygenase - $2(C O X-2)$ and their relationships with premature delivery in amniotic tissues.

Methods: Parturients were divided into three groups: 40 preterm-labor parturients (PTL group), 28 term-labor parturients (TL group), and 28 term non-labor parturients (TNL group). Changes in expressions of CBS, CSE and COX-2 were determined by Western blot (WB) in amniotic tissues of parturients in the three groups. The expression of COX - 2 was determined after the amniotic tissues of parturients in the TNL group were cultured in vitro and processed by exogenous hydrogen-sulfide $\left(\mathrm{H}_{2} \mathrm{~S}\right)$. Results: The expression level of COX - 2 was significantly lower in the TNL group, when compared with the PTL and TL groups $(p<0.05)$. The expression of CBS was increased in the order PTL $>T L>T N L$, with TNL group having the highest level, and there were significant differences in CBS expressions among the three groups $(p<0.05)$.

Conclusion: These results suggest that when the expressions of CBS and CSE are down-regulated, the decreased $\mathrm{H}_{2} \mathrm{~S}$ synthesis promotes the overexpression of $\mathrm{COX}-2$ by NF-kB signaling pathway, causing increased prostaglandin synthesis which results in premature delivery.
\end{abstract}

Keywords: Cystathionine $\beta$ - synthase, Cystathionine $\gamma$ - lyase, Cyclooxygenase - 2; Amniotic tissues; Preterm labor

\begin{abstract}
This is an Open Access article that uses a funding model which does not charge readers or their institutions for access and distributed under the terms of the Creative Commons Attribution License (http://creativecommons.org/licenses/by/4.0) and the Budapest Open Access Initiative (http://www.budapestopenaccessinitiative.org/read), which permit unrestricted use, distribution, and reproduction in any medium, provided the original work is properly credited.
\end{abstract}

Tropical Journal of Pharmaceutical Research is indexed by Science Citation Index (SciSearch), Scopus, International Pharmaceutical Abstract, Chemical Abstracts, Embase, Index Copernicus, EBSCO, African Index Medicus, JournalSeek, Journal Citation Reports/Science Edition, Directory of Open Access Journals (DOAJ), African Journal Online, Bioline International, Open-J-Gate and Pharmacy Abstracts

\section{INTRODUCTION}

Preterm labor $(\mathrm{PL})$ is the most common intrapartum complication, and also the first cause of neonatal illness and death [1]. In the world, the incidence of $\mathrm{PL}$ are 5 to $18 \%$, while in China, $\mathrm{PL}$ accounts for $7.1 \%$ [2], about two third of which are spontaneous [3]. The precise mechanism involved in the initiation of PL is not totally clear. Hydrogen sulfide $\left(\mathrm{H}_{2} \mathrm{~S}\right)$ is a gas with the scent of rotten eggs, and for long, has been regarded as a toxic waste which causes environmental and 
occupational hazards. However, recent studies suggest that endogenous $\mathrm{H}_{2} \mathrm{~S}$ plays an important role in human pregnancy and delivery. In mammals, endogenous $\mathrm{H}_{2} \mathrm{~S}$ is produced by the precursor $L$ - cysteine ( $L$ - cys) via two pyridoxal 5'-phosphate (PLP) - dependent enzymes: cystathionine $\beta$ - synthase (CBS) and cystathionine $\gamma$-lyase (CSE) [4].

Prostaglandin (PG) plays an important role in the initiation of human labor. It can induce contraction of uterine muscle and premature rupture of membranes, promote cervical ripening, and participate in the last process of initiation of labor. Arachidonic acid (AA) generates prostaglandin under the catalysis of prostaglandin G / H synthase - 2 (PGHS - 2), i.e.cyclooxygenase - 2 (COX - 2) [5]. Studies have found that $\mathrm{H}_{2} \mathrm{~S}$ reduces production of $P G$ by inhibiting expression of COX - 2 in microglia $[6,7]$.

In this study, the expressions of CBS, CSE and COX - 2 proteins were determined in the amniotic tissues of parturients who had PL, fullterm normal cesarean section delivery or fullterm normal vaginal delivery. In addition, the regulation of $\mathrm{H}_{2} \mathrm{~S}$ and its possible mechanism in expression of COX - 2 (i.e. PGHS - 2) were investigated in order to provide new train of thought and therapeutic target for the prevention and cure of PL.

\section{EXPERIMENTAL}

\section{Parturients}

In this study, 96 parturients who delivered at the First Maternity and Infant Hospital between September 1, 2014 and June 30, 2016 were recruited as subjects. They included 40 parturients with preterm vaginal delivery (spontaneous preterm - labor group, i.e., PTL group); 28 with full-term normal vaginal delivery (term - labor group, i.e., TL group), and 28 with full - term normal cesarean section delivery (term non - labor group, i.e., TNL group). Parturients with cardiovascular diseases and obesity prior to pregnancy or diabetes and hypertension in pregnancy, and those with complications of pregnancy such as intra-uterine growth retardation were excluded. In the PTL group, the average age was $27.31 \pm 6.42$ years, with a range of 22 - 34 years, and average gestational period was $34.58 \pm 2.17$ weeks, with a range of 30 - 36 weeks. In the TL group, the average age was $27.60 \pm 6.28$ years with a range of $21-34$, and average gestational period was $40.37 \pm 2.35$ weeks, with a range of 38 - 42 weeks. In the TNL group, the average age was $27.54 \pm 6.15$ years with a range of 22 - 36, and average gestational period was $40.36 \pm 2.42$ weeks, with a range of $37-41$ weeks. The study was approved by the Independent Ethics Committee of the Shanghai First Maternity and Infant Hospital affiliated to Tongji University (approval no. SH20140109), and followed the guidelines of Helsinki Declaration [8].

\section{Main reagents and instruments}

The reagents and equipment used in this study and their sources were: Western Blot electrophoretic apparatus (Bio-Rad Laboratories Pty Ltd); Western Blot electrophoresis and transmembrane system (Bio-Rad Laboratories Pty Ltd); UV Gel imaging system (Shanghai Furi Company); pre-stained protein molecular weight markers (Thermo Fisher Scientific); antibodies (Cell Signaling Technology); NaHS (SigmaAldrich); protease inhibitors (Sangon Biotech (Shanghai) Co., Ltd).

\section{Collection and treatment of specimen}

Postoperative amniotic tissues were excised and immediately placed in precooling physiological saline at $4.0^{\circ} \mathrm{C}$. After rinsing 3 times, the tissues were directly and quickly frozen in liquid nitrogen in cryogenic vials, and then transferred and stored at $-80{ }^{\circ} \mathrm{C}$. The tissues were taken out, blotted with absorbent paper, and put into special $2 \mathrm{~mL}$ EP tubes. Phosphatase inhibitors and RIPA lysate solution were added to the tubes, and then steel balls were put inside the tubes. The tissues were ground for one minute in a tissue grinder, and cooled in an ice bath for 30 min prior to centrifugation at $13,000 \mathrm{rpm}$ for 30 $\min$ at $4{ }^{\circ} \mathrm{C}$. The supernatant was transferred to a new $1.5 \mathrm{~mL}$ EP tube. The amount and composition of proteins in the supernatant protein were quantitatively analyzed using BCA protein quantitative kit.

\section{Western blot assay}

Electrophoresis was performed under constant voltage of $80 \mathrm{~V}$ and electrical current of $300 \mathrm{~mA}$. The electric voltage was modulated to $120 \mathrm{~V}$ after the samples entered the separation gel, and electrophoresis was continued until the separation gel was free of bromophenol blue. Then the membrane was transferred in ice bath. After membrane was transferred for two hours under constant current of $300 \mathrm{~mA}$ and electric voltage of $100 \mathrm{~V}$, the proteins in gel were transferred to cellulose acetate membranes. Subsequently, the prepared cellulose acetate membranes were taken out and rinsed thrice with 1xTBST solution (10 min each). Then the 
membranes were blotted with $5 \%$ skimmed milk and rinsed thrice with 1xTBST solution. Antibody for COX-2 / CBS / CSE / P65 antibody (first antibody) was applied at a dilution of $1: 500$ and the cellulose acetate membranes were incubated at $4{ }^{\circ} \mathrm{C}$ overnight. Next, the membranes were taken out again, shaken at room temperature slowly for $15 \mathrm{~min}$, and rinsed thrice with $1 \times$ TBST solution. Subsequently, the second antibody which was diluted with $1: 1000$ with 5 $\%$ skimmed milk was added and the cellulose acetate membranes were incubated at room temperature for $2 \mathrm{~h}$. Finally, the cellulose acetate membranes were exposed and developed with ECL Western blotting system, scanned and photographed using Bio-Rad chemiluminescence imaging instrument. The protein expressions were analyzed by gel analysis system. The control used to equalize protein in loading sample was GAPDH.

\section{Evaluation of COX-2 activity}

Amniotic tissues from term non-labor parturients were collected for primary culture in vitro. The tissues were processed using $\mathrm{H}_{2} \mathrm{~S}$ at different gradient concentrations, and changes in expression of COX - 2 were determined. Extrinsic $\mathrm{H}_{2} \mathrm{~S}$ was provided by $\mathrm{NaHS}$ solution. The amniotic tissues were cultured in vitro for 24 $\mathrm{h}$ and processed at concentrations of $1 \times 10^{-5} \mathrm{M}$, $2 \times 10^{-5} \mathrm{M}, 4 \times 10^{-5} \mathrm{M}$ and $8 \times 10^{-5} \mathrm{M}$. After $24 \mathrm{~h}$, they were collected for the determination of COX - 2 expression, while the supernatant of culture medium was also collected for the indirect assay of COX - 2 activity with Western blotting method.

\section{Statistical analysis}

Statistical analysis was performed using the statistical software, SPSS 19.0. Data are expressed as mean \pm standard deviation (mean \pm SD), and were analyzed by Student t-test for group comparison, analysis of variance was used to analyze the multiple groups comparison. Linear regression analysis was used for the comparison of correlation between two variables. Statistical significance was assumed at $p<0.05$.

\section{RESULTS}

\section{Expressions of COX - 2, CBS and CSE in amniotic tissues}

The expression level of COX - 2 was lowest in the TNL group, which was significantly different from those in the PTL and TL groups ( $p<0.05)$. There was no significant difference in COX - 2 expression between the PTL and TL groups $(p>$ $0.05)$. The expression of CBS was increased in the order: $\mathrm{PTL}>\mathrm{TL}>\mathrm{TNL}$. There were significant differences in CBS expressions amongst the three groups $(p<0.05)$. The expression level of CSE was the lowest in the PTL group, and was significantly different from those in the TL and TNL groups $(p<0.05)$. There was no significant difference in CSE expression between the TL and TNL groups $(p>0.05)$. These results are shown in Figure 1.
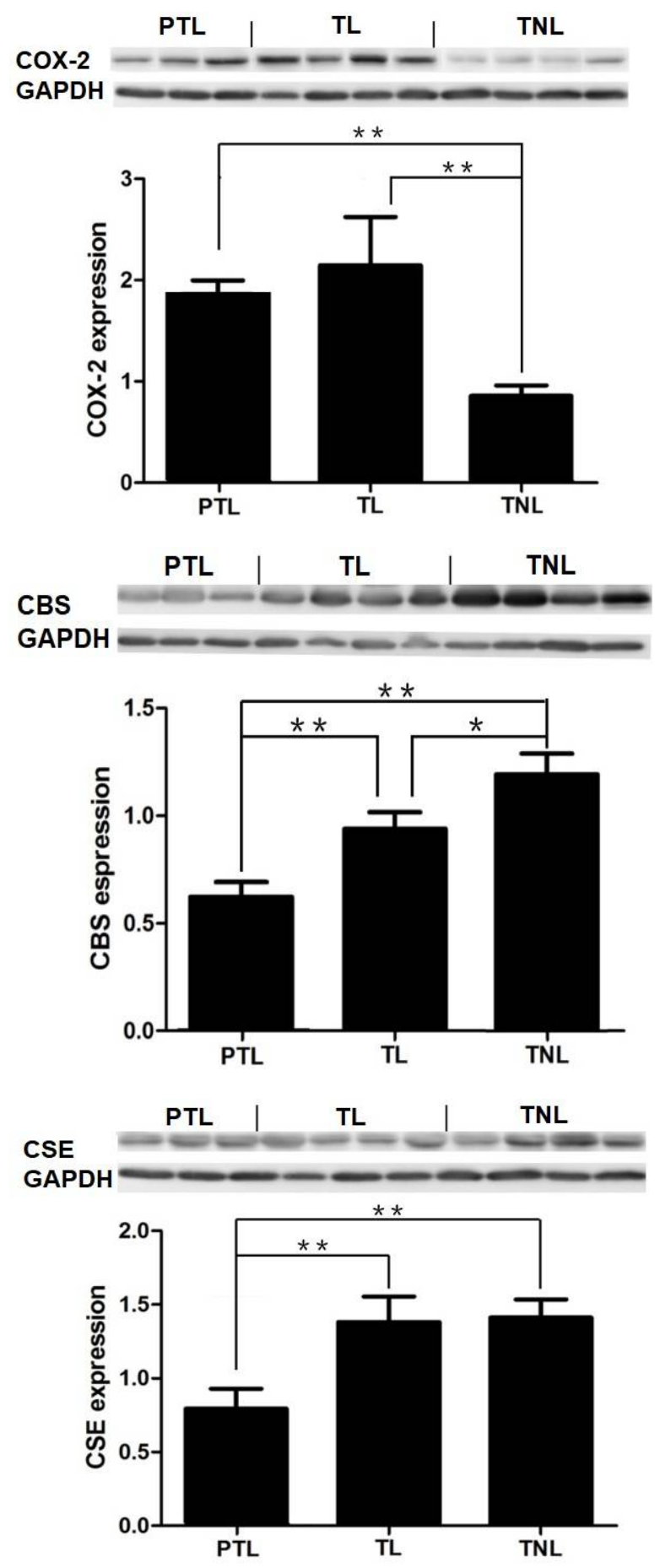

Figure 1: Expression levels of COX - 2, CBS and CSE in the three groups, $* p<0.05 ; * * p<0.01$ 

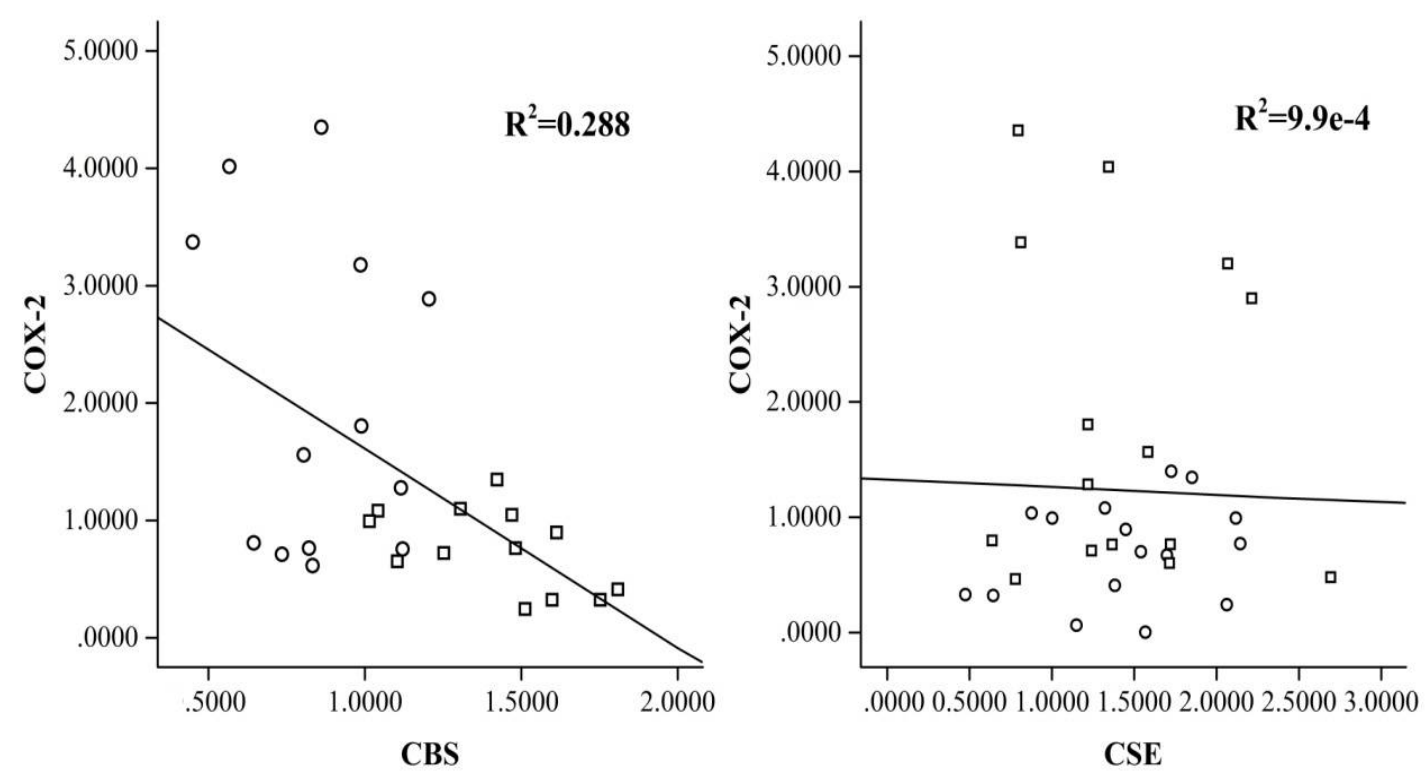

Figure 2: Linear regression analysis of expression levels of COX - 2, CBS and CSE

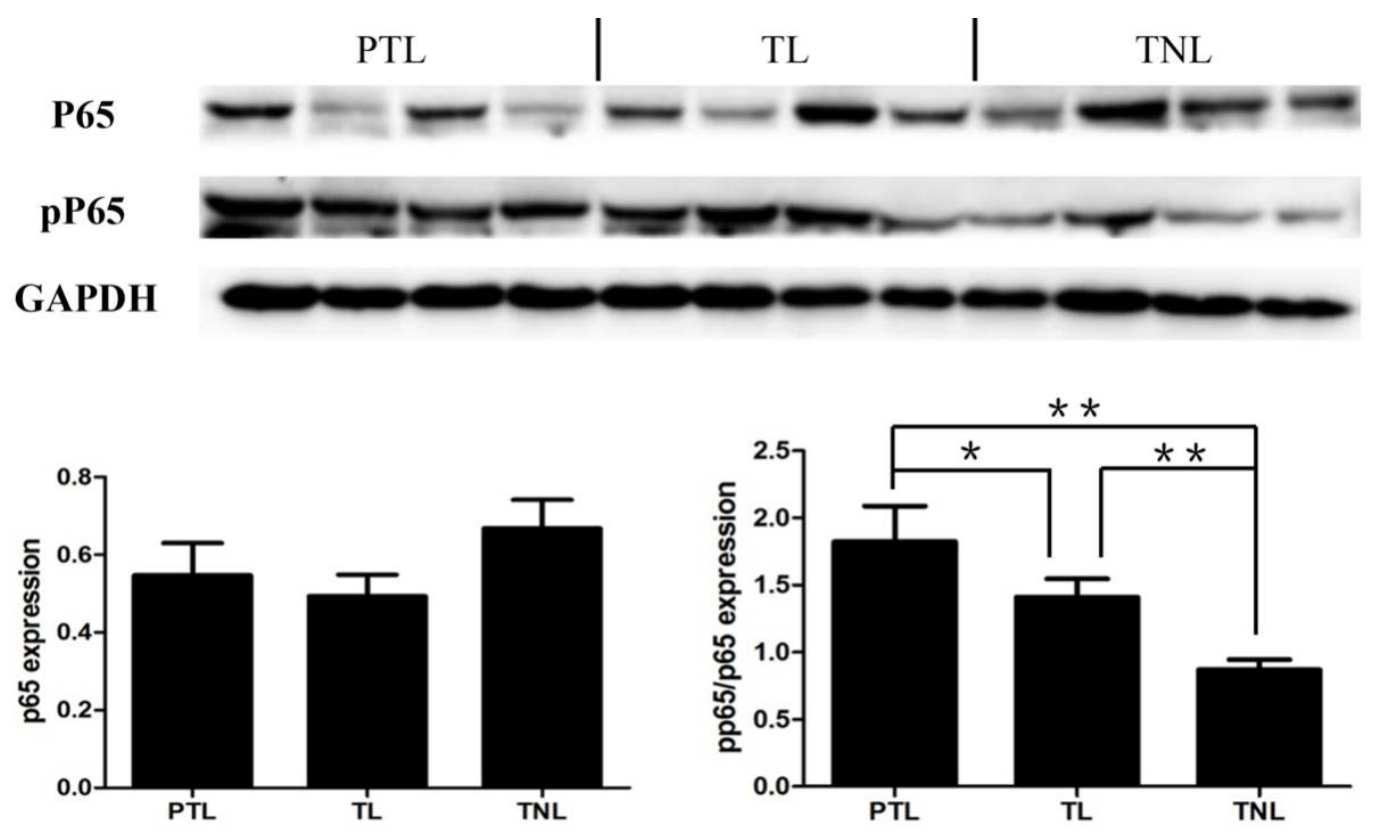

Figure 3: $\mathrm{P} 65$ expressions in the PTL, TL, and TNL groups; $* p<0.05, * * p<0.01$

Correlation among the expressions of COX 2, CBS and CSE in amniotic tissues

From linear regression model analysis, the expression level of CBS showed negative correlation with that of COX - $2(r=0.288)$. However, there was a weak correlation between the expression levels of CSE and COX - $2(r=$ $9.9 \times 10^{-4}$, Figure 2).

\section{Expression and phosphorylation of P65 protein in NF - kB signaling pathway}

Among the three groups, there were significant differences in expression of phosphorylated P65
( $p<0.05)$, but there were no significant differences in expression of un-phosphorylated P65 ( $p>0.05)$. The expressions of phosphorylated P65 in the PTL and TL groups were significantly higher than that in the TNL group, and in the PTL group, phosphorylated P65 expression was significantly higher than that in the TL group $(p<0.05)$. These results are shown in Figure 3.

Regulatory role of exogenous $\mathrm{H}_{2} \mathrm{~S}$ in expression and activity of COX-2 in human amniotic tissues

With increases in concentration of exogenous 


\section{COX-2 $-\cdots$}
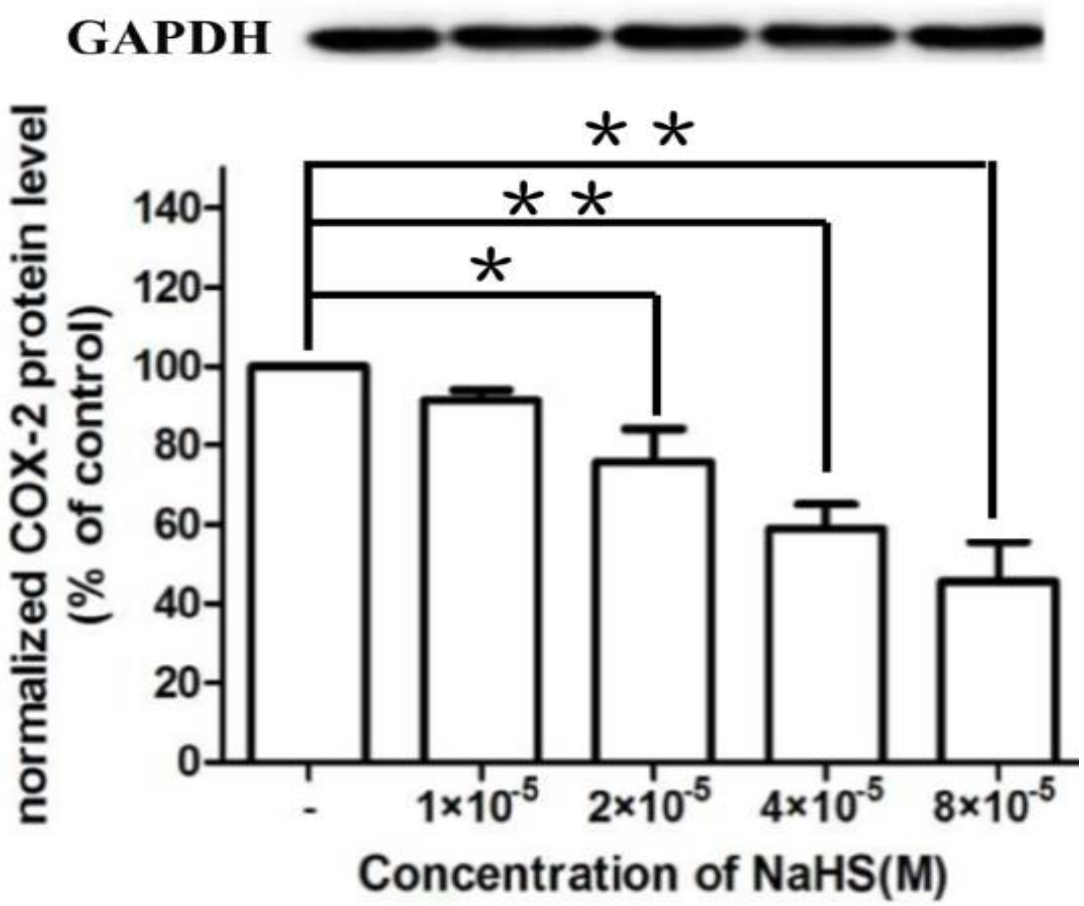

Figure 4: Regulatory role of exogenous $\mathrm{H} 2 \mathrm{~S}$ in COX - 2 expression in human amniotic tissues; $* p<0.05 ; * * p$ $<0.01$

$\mathrm{H}_{2} \mathrm{~S}$, the expression of COX-2 decreased continuously in human amniotic tissues (Figure 4).

\section{DISCUSSION}

Hydrogen sulfide $\left(\mathrm{H}_{2} \mathrm{~S}\right)$ is a colorless gas with the scent of rotten egg and the third signaling gas molecule found after nitric oxide (NO) and carbon monoxide (CO), which can regulate various physiological functions. L-cysteine is the substrate for the synthesis of $\mathrm{H}_{2} \mathrm{~S}$, and the enzymes involved in its synthesis are CSE, CBS and mercaptopyruvate sulfurtransferase (MPST or 3 - MST). Amongst these enzymes, CSE and CBS are found in various tissues and systems including uterine smooth muscle $[9,10]$. In this study, the expressions of CSE and CBS were also detected in amniotic tissues. Comparisons between the PTL, TL and TNL groups showed that the expressions of CSE and CBS in the PTL and TL groups were significantly decreased when compared with corresponding expressions in the TNL group; expressions of CSE and CBS were lowest in the PTL group, while expressions of CSE and CBS in the TL group were significantly lower than those in the TNL group. These results indicate that the expressions of CSE and CBS were significantly down-regulated in the PTL and TL groups, which resulted in the decrease $\mathrm{inH}_{2} \mathrm{~S}$ synthesis. In contrast, higher levels of $\mathrm{H}_{2} \mathrm{~S}$ delayed the occurrence of delivery and maintained the pregnancy state by inhibiting the contraction of uterine smooth muscle in the TNL group [11].

Regardless of whether parturients underwent premature labor or $\mathrm{TL}$, the processes of initiation of delivery were the same, which included regular uterine contraction, dilatation of cervix and rupture of membranes, all of which involve the important role of $P G[12,13]$. The main function of $P G$ is to stimulate smooth muscle cells of uterine wall, causing contraction of muscles which then induce the initiation of labor. In human intra-uterine tissues, $P G$ is synthesized mainly in fetal membranes, including amniotic membrane and chorion. The enzyme COX - 2 is an important rate-limiting protein in the synthesis of intra-corporeal PG [14]. It catalyzes the conversion of arachidonic acid to PG. In pregnancy, the functions of fetal membranes are to express COX - 2 lowly, reduce the synthesis of $P G$, maintain low levels of $P G$, reduce the transfer of $P G$ into uterine smooth muscle and maintain the pregnancy state [15]. However, as pregnancy progresses, the expression of COX-2 is increased gradually in the third trimester, resulting in increased PG synthesis in fetal membranes which then stimulate the contraction of uterine muscles and induce the initiation of labor $[16,17]$. In the present study, the 
expression of COX - 2 was determined in amniotic tissues in the PTL, TL and TNL groups. The results showed that the expression of COX 2 was the lowest in the TNL group and higher in the PTL and TL groups, which indicated that the high level of COX - 2 could induce the initiation of labor.

Subsequent correlation analyses between the expression of COX - 2 and the expressions of CSE and CBS showed a good linear negative correlation between the expressions of CBS and COX - 2, and a weak correlation between the expressions of CSE and COX - 2, which indicates that a regulatory role may exist between the expression of COX - 2 and the expressions of CSE and CBS.

However, it was not clear whether $\mathrm{H}_{2} \mathrm{~S}$ can inhibit the expression of COX - 2. In this study, the amniotic tissues from term non-labor parturients were collected for primary culture in vitro. The tissues were processed with $\mathrm{H}_{2} \mathrm{~S}$ at different gradient concentrations, and the changes in expression of COX - 2 were assayed. From the results, with increase in NaHS concentration, the expression of COX - 2 was gradually decreased and showed a dose-dependent effect, indicating that $\mathrm{H}_{2} \mathrm{~S}$ could regulate the synthesis and secretion of $\mathrm{PG}$ by regulating the expression of COX - 2 .

Hydrogen sulfide $\left(\mathrm{H}_{2} \mathrm{~S}\right)$ plays its physiological function by activating multiple signaling pathways such as MAPK and NF - kB signaling pathways $[18,19]$. P65 is an important subunit of nuclear factor kappa B (NF - kB) family. NF - $k B$ is an important intra-nuclear transcriptional factor (TF), which can be activated by lipopolysaccharide (LPS) and multiple inflammatory factors (e.g. IL 1 and TNF - $\alpha$ ) and transposed into the nucleus to activate transcription of target genes. A large number of studies have shown that NF- $k B$ is linked to the synthesis of $P G$ in intra-uterine tissues [20].

There are many binding sites of transcriptional factors in the promoter region of COX - 2, of which two NF - kB binding sites are associated with PG synthesis in intrauterine tissues [21]. In immortalized human amnion epithelial (WISH) cells, IL - 1 beta promotes the synthesis of PGs by activating NF- $k B$ to up-regulate the expression of COX - 2 [22]. In the present study, the expression and phosphorylation of P65 protein was assayed in NF - kB signaling pathway in the PTL, TL and TNL groups, and the effects of the related genes on premature labor were analyzed. The results showed significant differences in expression of phosphorylated P65 but no significant differences were seen in expressions of un-phosphorylated P65 among the three groups; expressions of phosphorylated P65 in the PTL and TL groups were significantly higher than those in the TNL group, while the expression in the PTL group was highest and significantly different from that in the TL group. These results indicate that the phosphorylation of $\mathrm{P} 65$ was related to the initiation of labor.

\section{CONCLUSION}

The expression levels of CBS, CSE and COX - 2 are closely related to the initiation of premature labor. The down-regulation of expressions of CBS and CSE causes a decrease in $\mathrm{H}_{2} \mathrm{~S}$ synthesis and reduction of inhibitory effect of $\mathrm{H}_{2} \mathrm{~S}$ on COX - 2 in human amniotic tissues. The upregulation of expression of COX - 2 results in increased PG synthesis and activation of $P G$ in placenta and fetal membranes, thereby inducing premature delivery. The findings of this study may lay the foundation for developing new methods of inhibiting the initiation of PL, and provide a new basis for the effective treatment of premature delivery. However, because of the complexity of mechanisms involved in the initiation of premature labor, the specific molecular mechanisms underlying the effects of $\mathrm{H}_{2} \mathrm{~S}, \mathrm{CBS}, \mathrm{CSE}$ and COX - 2 on the initiation of preterm delivery in amniotic membranes need to be further investigated.

\section{DECLARATIONS}

\section{Conflict of Interest}

No conflict of interest associated with this work.

\section{Contribution of Authors}

We declare that this work was done by the author(s) named in this article and all liabilities pertaining to claims relating to the content of this article will be borne by the authors, all authors read and approved the manuscript for publication. Xin Ni conceived and designed the study, Dan Liu, Tao Duan, Xing - ji You and Lu Gao collected and analyzed the data, Ming Liu wrote the manuscript. Ming Liu and Dan Liu contributed equally to the work.

\section{REFERENCES}

1. Zhong Y, Zhou J, Zhou M. Study on correlation between matrix metalloproteinase-9 expression and preterm premature rupture of membranes. Maternal and Child Health Care of China 2013; 28(9): 1502-1504. 
2. Blencowe $H$, Cousens $S$, Oestergaard $M Z$, Chou D, Moller AB, Narwal R, Adler A, Vera Garcia C, Rohde S, Say L, Lawn JE. National, regional, and worldwide estimates of preterm birth rates in the year 2010 with timetrends since 1990 for selected countries: a systematic analysis and implications. Lancet 2012; 379(9832): 2162-2172.

3. Frey HA, Klebanoff MA. The epidemiology, etiology, and costs of preterm birth. Semin Fetal Neonatal Med 2016; 21(2): 68-73.

4. Qu K, Lee SW, Bian JS, Low CM, Wong PT. Hydrogen sulfide: neurochemistry and neurobiology. Neurochem Int 2008; 52(1-2): 155-165.

5. Miao XP, Ou YQ, Wei $H$. Expression and significance of COX-2, PPARY and NF-KB p65 in ulcerative colitis tissues. World Chinese J Digestol 2010; 18(25): 2660 2665.

6. Renata COZ, Vincenzo $B$, Eleonora $D$, Stefano $F$, Giuseppe C, John LW. Hydrogen sulfide is an endogenous modulator of leukocyte-mediated inflammation. FASEB J 2006; 20(12): 2118-2120.

7. Liang WJ, Chen MJ, He JH. Role of ATP-sensitive potassium channels in inhibitory effect of hydrogen sulfide on high glucose-induced inflammation mediated by necroptosis in H9c2 cardiac cells. Chin J Pathophys 2016; 32: 1364-1369

8. General Assembly of the World Medical Association. World Medical Association Declaration of Helsinki: ethical principles for medical research involving human subjects. J Am Coll Dent 2014; 81(3): 14-8.

9. Pushpa $P$, Manu V, John $H$, Rui W, Ray JC. The endogenous production of hydrogen sulfide in intrauterine tissues. Reprod Biol Endocrinol 2009; 7: 1 10.

10. Wang $P$, Isaak $C K$, Siow $Y L$, Karmin O. Down regulation of cystathionine $\beta$-synthase and cystathionine $\gamma$-lyase expression stimulates inflammation in kidney ischemiareperfusion injury. Physiol Rep 2014; 2: e12251.

11. Hu R, Wei $Q$, Wang WQ. Relationship between endogenous hydrogen sulfide and premature labor. $J$ Tongji Univer (Med Sci) 2016; 37(2): 65-68.

12. Chao L, Ping Z, Wangsheng W, Wenjiao L, Qun S, ZiJiang $C$, Leslie $M$, Kang $S$. Inhibition of lysyl oxidase by prostaglandin E2 via EP2/EP4 receptors in human amnion fibroblasts: Implications for parturition. Mol Cell Endocrinol 2016; 424: 118-127.
13. Witkowski M, Witkowski M, Pawłowski K. Clinical observations on the course of oxytocin- or prostaglandin E2/oxytocin-induced parturition in mares. Pol J Vet Sci 2014; 17(2): 347-351.

14. Ruan $D$, So SP. Prostaglandin E2 produced by inducible COX-2 and mPGES-1 promoting cancer cell proliferation in vitro and in vivo. Life Sci 2014; 116(1): 43-50.

15. Yang F, Ma XD, Chen BL. Expression and clinical significance of fFN, COX-2, MMP-9 in spontaneous preterm delivery. Prog Obstet Gynecol 2014; 23(1): 3336.

16. Wu WX, Ma XH, Nathanielsz PW. Tissue-specific ontogenic expression of prostaglandin $H$ synthase 2 in the ovine myometrium, endometrium, and placenta during late gestation and at spontaneous term labor. Am J Obstet Gynecol 1999; 181(6): 1512-1519.

17. Fuchs AR, Rust W, Fields MJ. Accumulation of cyclooxygenase-2 gene transcripts in uterine tissues of pregnant and parturient cows: stimulation by oxytocin. Biol Reprod 1999; 60(2): 341-348.

18. Rong $H$, Jianqiang $L$, Xingji $Y$, Xiaoyan $Z$, Ning $H$, Xin $N$. Hydrogen sulfide inhibits the spontaneous and oxytocininduced contractility of human pregnant myometrium. Gynecol Endocrinol 2011; 27(11): 900-904.

19. Simões MR, Aguado A, Fiorim J, Silveira EA, Azevedo $B F$, Toscano CM, Zhenyukh O, Briones AM, Alonso MJ, Vassallo DV, et al. MAPK pathway activation by chronic lead-exposure increases vascular reactivity through oxidative stress/clooxygenase-2-dependent pathways. Toxicol Appl Pharmacol 2015; 283(2): 127-138.

20. Ackerman WE 4th, Summerfield TL, Vandre $D D$, Robinson JM, Kniss DA. Nuclear factor-kappa $B$ regulates inducible prostaglandin $E$ synthase expression in human amnion mesenchymal cells. Biol Reprod 2008; 78(1): 68-76.

21. Bakry OA, Samaka RM, Shoeib MA, Abdel ASM. Nuclear factor kappa $B$ and cyclo-oxygenase-2: two concordant players in psoriasis pathogenesis. Ultrastruct Pathol 2015; 39(1): 49-61.

22. Allport VC, Slater DM, Newton R, Bennett PR. NFkappaB and $A P-1$ are required for cyclo-oxygenase 2 gene expression in amnion epithelial cell line (WISH). Mol Hum Reprod 2000; 6(6): 561-565. 